\title{
Alkol ve Madde Bağımlılığı Olan Bireylerde İştah, Beslenme Durumu ve Yaşam Kalitesi İlişkisi
}

\author{
Association of Appetite, Nutritional Status and Quality of Life in Alcohol and Substance Abusers
}

\section{Özge Küçükerdönmez ${ }^{1}$, Murat Urhan² ${ }^{2}$ Eda Köksal ${ }^{3}$}

Geliş tarihi/Received: 22.06.2018 • Kabul tarihi/Accepted: 14.08.2018

\section{ÖZET}

Amaç: Bu çalışma alkol ve madde bağımlılığı olan bireylerin iştah ve beslenme durumlarının saptanması ve karşılaştırılması, beslenme alışkanlıklarının ve beslenme durumu ile yaşam kaliteleri arasındaki ilişkinin belirlenmesi amacıyla yapılmıştır.

Bireyler ve Yöntem: Çalışma Manisa Ruh Sağlığı ve Hastalıkları Hastanesi AMATEM Servisi’nde yatan, yaşları 20-60 yıl arasında değişen, 167 madde ve 46 alkol bağımlısı olmak üzere toplam 213 erkek birey üzerinde yürütülmüştür. Bağımlılara yüz yüze görüşme yöntemi ile anket uygulanmış, genel bilgiler, beslenme alışkanlıkları, 24 saatlik besin tüketim durumu saptanmış, Basitleştirilmiş Beslenme İştah Anketi, Kısa Beslenme Değerlendirme Anketi (SNAQ), Besin Çeşitliliği Skoru (DDS), Kısa Form Yaşam Kalitesi Ölçeği (SF-36) uygulanmış ve antropometrik ölçümleri alınmıştır.

Bulgular: Bu çalışmada SNAQ’ya göre madde kullanan bireylerin \%71.3’ünde, alkol kullanan bireylerin \%69.6’sında ağır malnütrisyon bulunduğu, ayrıca madde kullananların \%87.4'ünde, alkol kullananların \%93.5'inde iştahın bozulmasına bağlı olarak gelecek 6 ayda önemli düzeyde ağırlık kaybı riski bulunduğu belirlenmiştir. Alkol bağımlılarının \%78.3’ünün, madde bağımlılarının \%69.5'inin DDS’nin yetersiz olduğu, tüm grup değerlendirildiğinde ise bireylerin genellikle tek öğ̈̈n tükettikleri (\%57.7) ve bu durumun alkol bağımlılarında (\%76.1) madde kullanan bireylere (\%52.7) göre daha yaygın olduğu bulunmuştur ( $\left.\chi^{2}: 8.880, \mathrm{p}<0.05\right)$. Madde bağımlılarının antropometrik ölçümleri ile vücut bileşimi değerlerinin alkol kullanan bireylerden daha düşük olduğu saptanmıştır $(\mathrm{p}<0.01)$. Ayrıca madde bağımlılarında fiziksel fonksiyonları yerine getirebilme ile BKİ, malnütrisyon, iştah durumu ve DDS puanları arasında önemli ilişki olduğu belirlenmiştir (p<0.05). Alkol bağımlarında ise sosyal işlevsellik, BKİ ve ÜOKÇ ile ruhsal sağlık, iştah durumu ve malnütrisyonla ilişkilidir (p<0.05).

Sonuç: Sonuç olarak alkol ve madde bağımlılarının beslenme ve iştah durumunun bozulduğu ve yaşam kalitelerinin oldukça kötü olduğu belirlenmiştir. Tedaviye alınan kişilerde mutlaka beslenme durumu uygun değerlendirme araçlarıyla incelenmeli ve farmakolojik tedavinin yanında kişiye özel bir beslenme programı uygulanmalıdır.

Anahtar kelimeler: Alkol ve madde bağımlılı̆̆l, diyet çeşitliliği skoru, beslenme durumu, malnütrisyon, antropometrik ölçümler

\section{ABSTRACT}

Aim: This study was conducted to detect the appetite and nutritional status of alcohol and substance abusers and to determine the relationship between their dietary habits, nutrition, and quality of life.

Subjects and Method: The study consisted of 167 substance- and 46 alcohol- abusers, in total, 213 male participants who are

1. İletişim/Correspondence: Ege Üniversitesi, Sağlık Bilimleri Fakültesi, Beslenme ve Diyetetik Bölümü, İzmir, Türkiye • E-posta: dytyasemincakir@gmail.com (1) https://orcid.org/0000-0003-2228-8917
2. Ege Üniversitesi, Sağlık Bilimleri Fakültesi, Beslenme ve Diyetetik Bölümü, İzmir, Türkiye • (1) https://orcid.org/0000-0002-5812-5493

3. Gazi Üniversitesi, Sağlık Bilimleri Fakültesi, Beslenme ve Diyetetik Bölümü, Ankara, Türkiye - 니 https://orcid.org/0000-0002-7930-9910 
hospitalized in the AMATEM Service of the Manisa Hospital of Mental Health and Disease. The ages of the participants ranged from 20 to 60 years. The researcher conducted a survey through face-to-face interviews, obtained general information, and determined their dietary habits and food consumption over 24 hours. The Simplified Nutritional Appetite Questionnaire, Short Nutritional Assessment Questionnaire (SNAQ), Dietary Diversity Score (DDS) and Short Form Quality of Life Questionnaire (SF-36) were used to collect data, including the subjects' anthropometric measurements.

Results: Based on the SNAQ $71.3 \%$ of the individuals who abuse substances and $69.6 \%$ of alcohol users have severe malnutrition; $87.4 \%$ of substance abusers and $93.5 \%$ of alcohol abusers are at risk of significant weight loss during the following 6 month-period caused by loss of appetite. The DDS of $78.3 \%$ of the alcohol abusers and $69.5 \%$ of the substance abusers was determined to be insufficient; when evaluated as a group, these individuals usually have a single meal per day (57.7\%). This is more common among alcohol abusers (76.1\%) than substance abusers $(52.7 \%)\left(\chi^{2}=8.880, p<0.05\right)$. The values of anthropometric measurements and body composition of substance abusers are found to be lower than those of alcohol abusers $(\mathrm{p}<0.01)$. Furthermore, there is a significant relationship between substance abusers' performing physical functions and their BMI, malnutrition, appetite, and DDS $(\mathrm{p}<0.05)$. Social functionality of alcohol abusers was related to BMI and MUAC, mental health, appetite, and malnutrition $(\mathrm{p}<0.05)$.

Conclusions: This study demonstrates vital conclusions showing that nutritional and appetite status of both the alcohol and the substance abusers have deteriorated; and their quality of life was quite unsatisfactory. The nutritional status of people treated for addiction should be investigated through appropriate assessment tools, and each patient should be provided with a personal dietary program as well as pharmacological treatment.

Keywords: Alcohol and substance abuse, dietary variety score, nutrition status, malnutrition, anthropometric measurements

\section{GİRIŞ}

Alkol ve madde bağımlılığı bireysel ve toplumsal düzeyde olumsuz sağlık sonuçlarıyla ilişkili önemli bir halk sağlığı sorunudur. Bağımlılık bireylerde morbidite ve mortalite oranının artmasının yanı sıra işsizlik, suç işleme, aile içi sorunlar ve toplum tarafından dışlanma gibi sosyal sorunlara neden olmaktadır (1,2). Küresel düzeyde 15 yaş ve üzerindeki bireylerde alkol kullanım oranının \%38 olduğu ve aşırı alkol tüketen bireylerin oranının ise \%16 olduğu tahmin edilmektedir (3). Madde kullanım oranının ise \%5.6 düzeyinde olduğu, yaklaşı 275 milyon kişinin en az bir maddeyi kullandığı ve son ylllarda madde kullanım oranlarında ciddi artışların gözlendiği bildirilmektedir (4).

Alkol ve madde bağımlılarında genellikle beslenme alışkanlıkları değişmekte ve yanlış beslenme uygulamaları yaygın olarak görülmektedir. Bağımlılık yapan maddelerin farmakolojik özelliklerindeki değişkenlikler, bireylerin beslenme durumları ve iştahları üzerine farklı etkiler yapmaktadır (5). Alkol kullanımı ise primer ve sekonder malnütrisyona neden olmaktadır. Primer malnütrisyon alkol tüketiminin artmasına bağlı olarak besin alımının önemli düzeyde azalmasıyla ortaya çıkmaktadır (6). Alkolün gastrointestinal bölgede oluşturduğu hasar sonucu gelişen iştah kaybı, bulantı, kusma, diyare, sindirim ve emilim bozuklukları ise sekonder malnütrisyona neden olmaktadır (7).

$\mathrm{Bu}$ çalışma alkol ve madde bağımlılığı olan bireylerin iştah ve beslenme durumlarının saptanması ve karşılaştırılması, beslenme alışkanlıklarının ve beslenme durumu ile yaşam kaliteleri arasındaki ilişkinin belirlenmesi amacıyla planlanmış ve yürütülmüştür.

\section{BİREYLER VE YÖNTEM}

$\mathrm{Bu}$ çalışma Manisa Ruh Sağlığı ve Hastalıkları Hastanesi AMATEM Servisi'ne DSM-5 tanı kriterlerine göre alkol ve madde kullanım bozukluğu tedavisi için yatan, yaşları 20-60 yıl arasında değişen, 167 madde ve 46 alkol bağımlısı olmak üzere toplam 213 erkek 
birey üzerinde yürütülmüştür. Bağımlı bireyler için çalışmaya dahil olma kriterleri detoksifikasyon sürecine başlanmamış olmaması, hepatit-B, hepatit-C ve HIV (+) enfeksiyonu bulunmaması, psikotik bozukluk hikayesi, metabolik, nörolojik ve otoimmün hastalığının olmaması ve son bir yıl içinde bireyin bağımlılık için tedavi görmemiş olması şeklinde kabul edilmiştir.

Servise yatışı yapıldığında madde etkisinde olan, servis sorumlu doktoru tarafından çalışmaya dahil edilmesi uygun bulunmayan ve dahil edilme kriterlerini karşılamayan hastalar çalışma dışında bırakılmıştır. Bireylerin hangi maddeyi ve/veya maddeleri kullandıkları sözel olarak sorulmuş ancak bireylerin kullandıkları maddelerin belirlenmesinde idrar toksikoloji sonuçları baz alınmıştır. İdrar toksikoloji sonuçları ve bireylerin verdikleri cevaplar arasında \%98 uyum görülmüştür. Çalışmanın etik izni 25.02.2016 tarih ve E.6792 sayı ile Gazi Üniversitesi Etik Komisyonundan alınmıştır.

Bu çalışmada bağımlılara yüz yüze görüşme yöntemi ile anket uygulanmış, genel bilgiler, beslenme alışkanlıkları, 24 saatlik besin tüketim durumu saptanmış, Basitleştirilmiş Beslenme İştah Anketi, Kısa Beslenme Değerlendirme Anketi, Besin Çeşitliliği Skoru, Kısa Form Yaşam Kalitesi Ölçeği uygulanmış ve bazı antropometrik ölçümleri alınmıştır.

\section{Antropometrik Ölçümler}

Bireylerin vücut ağırlığı, boy uzunluğu, bel ve kalça çevresi ölçümleri araştırmacılar tarafindan tekniğine uygun olarak alınmıştır (8). Boy uzunluğu ölçümü Seca marka stadiyometre (Seca mod. 240 CE 0123, Germany) ile $0.1 \mathrm{~cm}$ hata payıyla yapılmıştır. Vücut ağırlığı ve vücut bileşimi (vücut yağ \%, yağsız vücut kütlesi) ölçümleri Tanita BC-532 marka biyoelektrik impedans cihazı kullanılarak alınmıştır. Bel ve kalça çevresi ölçümleri esnemeyen mezür ile $0.1 \mathrm{~cm}$ hata payıyla alınmıştır. Beden kütle indeksi (BKİ-kg/m²), bel/kalça oranı ve bel/boy oranı hesaplanmıştır (8-10).

\section{Basitleştirilmiş Beslenme İştah Anketi (Simplified Nutritional Appetite Questionnaire)}

Katılımcıların iştah durumunun değerlendirilmesi Basitleştirilmiş Beslenme İştah Anketi ile yapılmıştır. Basitleştirilmiş Beslenme İştah Anketi dört sorudan oluşmaktadır. Her bir sorunun cevabına göre birle beş puan aralığında değer verilmektedir. Toplam skor katılımcıların cevaplarına karşılık gelen puanlar toplanarak hesaplanmakta ve skorun $\leq 14$ puan olması kişinin sonraki 6 ay içinde en az \%5 ağırlık kaybı için ciddi risk taşıdığını göstermektedir $(11,12)$.

\section{Kısa Beslenme Değerlendirme Anketi (Short Nutritional Assessment Questionnaire-SNAQ)}

Malnütrisyonunerkentanımlanmasıvefarkındalığının sağlanması için Kısa Beslenme Değerlendirme Anketi (SNAQ) hastanın beslenmesi ile ilgili üç soru içermektedir. Toplam skor katılımcıların cevaplarına karşllık gelen puanlar toplanarak hesaplanmakta ve skorun 0-1 puan olması hastanın iyi beslendiğini, 2 puan olması orta dereceli malnütrisyon olduğunu ve beslenme müdahalesi olması gerektiğini, $\geq 3$ puan olması ise ağır malnütrisyonun varlığını ve diyetisyen müdahalesi gerektiğini göstermektedir (13).

\section{Besin Çeşitliliği Skoru (Dietary Diversity Score- DDS)}

Besin çeşitliliğini belirlemek için bireylerden 24-saatlik geriye dönük besin tüketim kaydı alınarak, tüketilen besinler besin gruplarına ayrılmıştır. Bireysel besin çeşitliliği skoru (DDS) 9 besin grubu içermektedir: i) tahıllar, beyaz kökler ve yumrular, ii) koyu yeşil yapraklı sebzeler, iii) diğer A vitamininden zengin sebze ve meyveler, iv) diğer sebze ve meyveler, v) sakatatlar, vi) et ve balık ürünleri, vii) yumurtalar, viii) baklagiller, kuruyemiş ve tohumlar, ix) süt ve süt ürünleri. Bireysel DDS hesaplanırken katılımcı besini tüketiyorsa 1 puan, tüketmiyorsa 0 puan almaktadır. Bireysel DDS 0-3 puan ise düşük, 4-5 puan ise orta, >6 puan ise yüksek besin çeşitliliği skoru şeklinde değerlendirilmektedir (14). 
Yaşam Kalitesi Ölçeği Kısa Form-36 (36-Item Short Form Survey, SF-36)

Yaşam kalitesinin değerlendirmesi için yaygın olarak kullanılan bir ölçek olan Tıbbi Sonuç Araştırması (Medical Outcome Study, MOS) Kisa Form-36 (SF36) kullanılmıştır. Ölçek Ware ve Sherbourne (1992) tarafindan geliştirilmiş, Türkçe güvenilirlik ve geçerlilik çalışması ise Koçyiğit ve arkadaşları tarafından yapılmıştır. Sağlığın sekiz bileşende incelendiği bu ölçekte yüksek puanlar sağlıkta daha iyi bir düzeyi işaret etmektedir. Ölçekte 100 puan üzerinden puanlama yapılmakta ve alınan puanlar her bileşen için 0 ile 100 puan arasında değişmektedir $(15,16)$.

\section{İstatistiksel Analizler}

Bireylerden elde edilen nitel veriler sayı (S) ve yüzde (\%) olarak ifade edilmiş ve kategorik değişkenler arası ilişkiyi incelemek için Ki-kare testi kullanılmıştır. Nicel verilerin ortalama $(\overline{\mathrm{X}})$ ve standart sapma (S) değerleri verilerek gruplar arasındaki farklılıklar parametrik verilerde bağımsız gruplarda t-testi kullanılarak değerlendirilmiştir. Bireylere ait parametreler arasındaki ilişkilerin incelenmesi için Pearson korelasyon testi kullanılmıştır. İstatistiksel önemlilik düzeyi $\mathrm{p}<0.05$ olarak kabul edilmiştir. Tüm analizler IBM SPSS Statistics 22.0 istatistik paket programı kullanılarak yapılmıştır.

\section{BULGULAR}

Madde ve alkol bağımlılarının yaş ortalamaları sirasiyla $25.3 \pm 5.73$ (18-48) yıl ve $44.4 \pm 8.36$ (26-59) yll olarak belirlenmiştir ( $\mathrm{p}<0.01)$. Madde bağımlılarının \%80.8’i bekar ve \%68.9'u işsiz, alkol bağımlılarının ise \%54.3’ü bekâr, \%69.56'sı işsizdir ( $p>0.05$ ). Alkol bağımlıları ortalama $16.5 \pm 11.6$ yıldır alkol kullanırken, madde bağımlıları ortalama 6.6 \pm 3.54 ylldır madde kullanmaktadır $(\mathrm{p}<0.01)$. Kısa Beslenme Değerlendirme Anketi ile yapılan değerlendirme sonucunda madde kullanan bireylerin \%71.3'ünde ağır malnütrisyon bulunduğu sadece \%26.4'ünün yeterli beslendiği saptanmıştır. Alkol bağımlılarında ise ağır malnütrisyonlu birey oranı \%69.6 olarak belirlenirken, yeterli beslenenler \%21.7 oranında bulunmuştur ( $p>0.05$ ) (Şekil 1A).
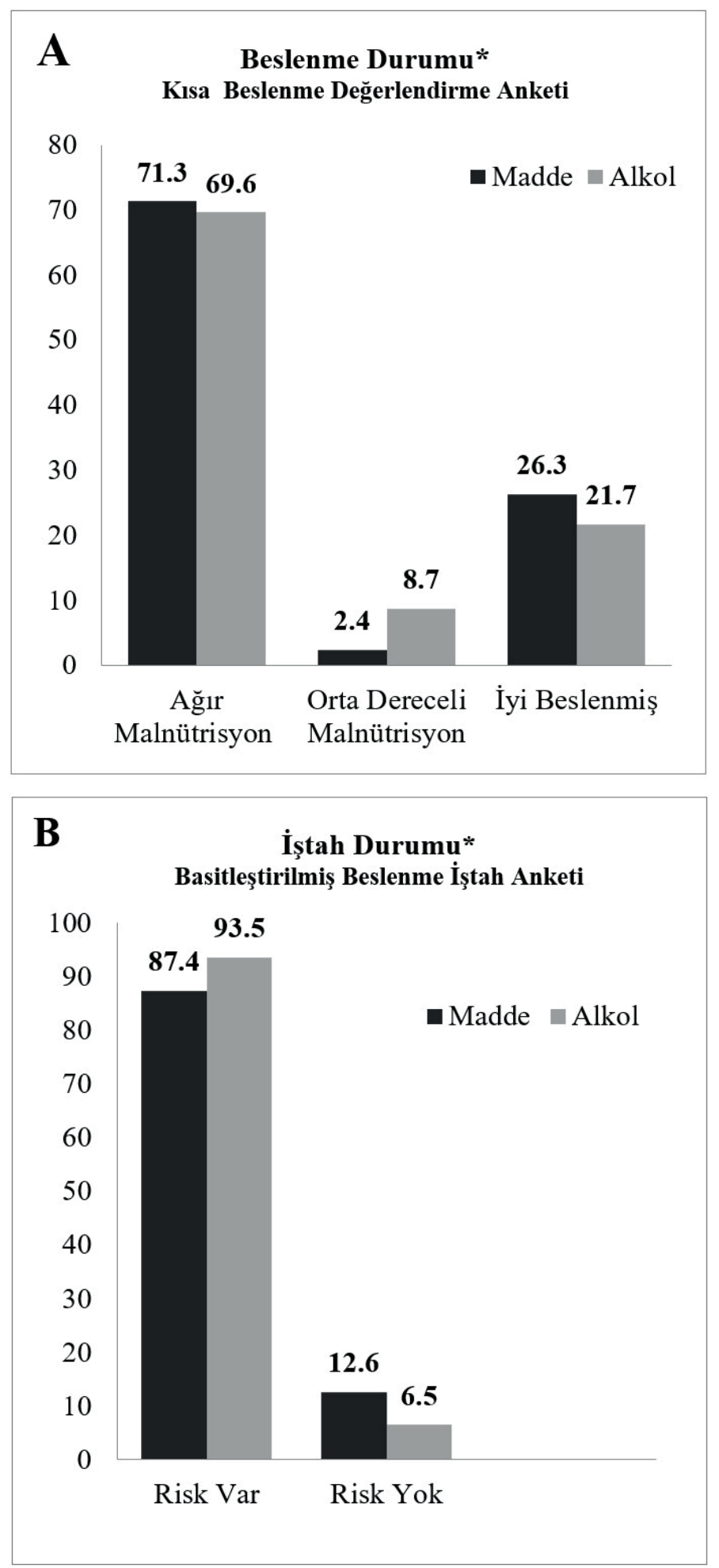

Şekil 1. Madde ( $n=167)$ ve alkol bağımlılarının $(n=46)$ beslenme ve iştah durumları

A) Beslenme durumu (*p>0.05), B) İştah durumu (*p>0.05) 
Basitleştirilmiş Beslenme İştah Anketi’ne göre yapılan değerlendirmede madde bağımlılarının ortalama puanı 9.7 \pm 3.32 , alkol bağımlılarının ise $8.2 \pm 3.00$ olarak saptanmıştır ( $\mathrm{p}<0.05)$. Bu ankete göre gelecek 6 ay içinde iştah kaybı nedeniyle \%5'in üzerinde ağırlık kaybı riski madde bağımlılarının \%87.4'ünde, alkol bağımlılarının ise \%93.5'inde görülmektedir. Alkol bağımlılarında ağırlık kaybı riski madde kullanan bireylerden fazla olsa da, bu farkın istatistiksel açıdan anlamlı olmadığı saptanmıştır ( $\mathrm{p}>0.05)$ (Şekil 1B).

Bireylerin DDS puanı ve beslenme alışkanlıkları Tablo 1'de gösterilmiştir. Madde bağımlılarının \%69.5'inin, alkol bağımlılarının \%78.3'ünün yetersiz DDS puanına sahip olduğu, buna karşılık sadece madde bağımlılarının \%13.1'nin yeterli DDS puanına sahip olduğu belirlenmiştir. Gruplar arasında istatistiksel olarak fark saptanmamıştır $(p>0.05)$. Tüm grup değerlendirildiğinde ise bireylerin \%71.3'ünün DDS puanın yetersiz grupta yer aldığı, bireylerin sadece \%10.4'ünün yeterli diyet çeşitliliğine sahip olduğu bulunmuştur.

Günlük öğün tüketim durumları değerlendirildiğinde madde kullanan bireylerin \%4.8'inin hiç ana öğün tüketmediği, \%52.7’sinin ise günde sadece bir öğün tükettiği saptanmıştır. Alkol bağımlılarında hiç ana öğün tüketmeyen birey bulunmazken, günde bir öğün tüketen bireylerin (\%76.1) sayısı madde bağımlılarından daha fazla düzeyde bulunmuştur ( $p$ <0.05). Buna karşılık madde bağımlılarında günde iki ve üç öğün tüketenlerin oranı alkol bağımlılarından daha yüksek düzeylerdedir $(\mathrm{p}<0.05)$ (Tablo 1). Tüm grup değerlendirildiğinde ise bireylerin \%57.7’sinin günde sadece tek öğün tükettiği belirlenmiştir.

Tablo 1. Bireylerin diyet çeşitliliği puanı sınıflaması ve tükettiği ana öğün sayısı

\begin{tabular}{|c|c|c|c|c|c|c|c|c|}
\hline \multirow[t]{2}{*}{ DDS } & \multicolumn{2}{|c|}{$\begin{array}{c}\text { Tüm gruplar } \\
(n=213)\end{array}$} & \multicolumn{2}{|c|}{$\begin{array}{l}\text { Madde bağımlıları } \\
(n=167)\end{array}$} & \multicolumn{2}{|c|}{$\begin{array}{l}\text { Alkol bağımlıları } \\
(n=46)\end{array}$} & \multirow{2}{*}{$\chi^{2}$} & \multirow[t]{2}{*}{$\mathbf{p}$} \\
\hline & $\mathbf{n}$ & $\%$ & $\mathbf{n}$ & $\%$ & $\mathbf{n}$ & $\%$ & & \\
\hline \multicolumn{9}{|l|}{ Diyet çeşitliliği } \\
\hline Yetersiz (0-3 puan) & 152 & 71.3 & 116 & 69.5 & 36 & 78.3 & \multirow{3}{*}{20.144} & \multirow{3}{*}{0.335} \\
\hline Orta (4-5 puan) & 39 & 18.3 & 29 & 17.4 & 10 & 21.7 & & \\
\hline Yeterli (6 ve üzeri) & 22 & 10.4 & 22 & 13.1 & - & - & & \\
\hline \multicolumn{9}{|l|}{ Ana öğün sayısı } \\
\hline Hiç tüketmeyen & 8 & 3.8 & 8 & 4.8 & - & - & \multirow{4}{*}{8.880} & \multirow{4}{*}{$0.031^{*}$} \\
\hline 1 ana öğün & 123 & 57.7 & 88 & 52.7 & 35 & 76.1 & & \\
\hline 2 ana öğün & 58 & 27.2 & 50 & 29.9 & 8 & 17.4 & & \\
\hline 3 ana öğün & 24 & 11.3 & 21 & 12.6 & 3 & 6.5 & & \\
\hline
\end{tabular}

${ }^{*} p<0.05$, Pearson ki-kare testi

Tüm antropometrik ölçümler ile vücut bileşimi parametrelerinin alkol bağımlılarında madde bağımlılarına göre daha yüksek olduğu saptanmıştır $(p<0.01)$. Ağırlık kaybı miktar ve oranı incelendiğinde ise madde bağımlılarında daha yüksek olduğu ancak istatistiksel olarak gruplar arasında fark olmadığ belirlenmiştir ( $\mathrm{p}>0.05)$ (Tablo 2).

Bireylerin BKİ sinıflamasına göre dağılımları değerlendirildiğinde ise madde kullanan bireylerin \%13.2'sinin zayıf, \%86.8'inin normal aralıkta yer aldığı bulunurken, alkol kullanan bireylerin \%8.7'sinin zayıf, \%76.1'inin normal, \%10.9'unun hafif şişman ve \%4.3'ünün obez olduğu belirlenmiştir $(p<0.01)$ (Veriler tabloda gösterilmemiştir).

Alkol ve madde bağımlılarında SF-36 Yaşam Kalitesi Ölçeği alt ölçek puanları Tablo 3’te verilmiştir. Buna göre madde bağımlılarında ağrı alt ölçek puanının önemli düzeyde düşük olduğu saptanırken, alkol bağımlılarında fiziksel fonksiyon alt ölçek puanının önemli düzeyde düşük olduğu belirlenmiştir $(p<0.01)$. 
Tablo 2. Bireylerin antropometrik ölçümleri, BKİ değeri ve vücut ağırlığı kaybı

\begin{tabular}{lccc}
\hline Antropometrik ölçümler & Madde bağımlıları (n= 167) & Alkol bağımlıları (n= 46) & p \\
\hline Vücut ağırlığı (kg) & $\overline{\mathrm{X}}_{ \pm} \mathbf{S}$ & $70.7 \pm 12.26$ & $0.001^{* *}$ \\
Boy uzunluğu (cm) & $63.8 \pm 7.38$ & $175.1 \pm 6.19$ & 0.976 \\
BKİ (kg/m²) & $175.1 \pm 5.78$ & $23.1 \pm 3.52$ & $0.001^{* *}$ \\
Bel çevresi (cm) & $20.8 \pm 1.89$ & $89.3 \pm 10.58$ & $0.001^{* *}$ \\
Kalça çevresi (cm) & $77.9 \pm 5.50$ & $96.7 \pm 5.90$ & $0.001^{* *}$ \\
Bel/kalça oranı & $90.9 \pm 4.76$ & $0.9 \pm 0.07$ & $0.001^{* *}$ \\
Bel/boy oranı & $0.9 \pm 0.04$ & $0.5 \pm 0.06$ & $0.001^{* *}$ \\
Vücut yağ yüzdesi (\%) & $0.4 \pm 0.03$ & $16.3 \pm 5.31$ & $0.001^{* *}$ \\
Yağsız vücut kütlesi (kg) & $11.9 \pm 3.50$ & $56.9 \pm 6.75$ & $0.033^{*}$ \\
Ağırlık kaybı (kg, son 6 ay) & $54.6 \pm 6.10$ & $7.7 \pm 1.80$ & 0.372 \\
Ağırlık kaybı yüzdesi (\%, son 6 ay) & $8.5 \pm 3.78$ & $10.11 \pm 2.29$ & 0.127 \\
\hline
\end{tabular}

${ }^{*} p<0.05,{ }^{* *} p<0.01$, Bağımsız gruplarda t-testi

BKİ: Beden kütle indeksi

Tablo 3. Bireylerin Yaşam Kalitesi Ölçeği (SF-36) puanları

\begin{tabular}{lccc}
\hline SF-36 & Madde bağımlıları (n= 167) & Alkol bağımlıları (n= 46) & p \\
\hline Fiziksel fonksiyon & $\overline{\mathrm{X}}_{ \pm \mathbf{S}}$ & $\mathbf{\mathrm { X }} \pm \mathbf{S}$ & $0.007^{*}$ \\
Fiziksel rol güçlüğü & $12.8 \pm 27.43$ & $42.1 \pm 30.28$ & 0.531 \\
Emosyonel rol güçlüğü & $11.6 \pm 31.30$ & $16.3 \pm 30.05$ & 0.116 \\
Canlılık & $16.6 \pm 18.73$ & $21.7 \pm 39.88$ & 0.298 \\
Ruhsal sağlık & $35.8 \pm 18.76$ & $19.9 \pm 19.04$ & 0.364 \\
Sosyal işlev & $13.2 \pm 19.37$ & $33.1 \pm 14.14$ & 0.277 \\
Ağrı & $51.3 \pm 34.73$ & $16.6 \pm 14.92$ & $0.006^{*}$ \\
Genel sağlık algısı & $29.8 \pm 16.05$ & $67.0 \pm 29.84$ & 0.594 \\
\hline Fiziksel sağlık özeti & $\mathbf{3 8 . 9} \pm \mathbf{8 . 8 6}$ & $31.2 \pm 12.19$ & $\mathbf{0 . 8 7 2}$ \\
Ruhsal sağlı özeti & $\mathbf{2 5 . 4 \pm 8 . 6 4}$ & $\mathbf{3 9 . 1} \pm \mathbf{9 . 8 4}$ & $\mathbf{0 . 5 1 3}$ \\
\hline
\end{tabular}

${ }^{*} p<0.01$, Bağımsız gruplarda t-testi

Gruplar arasında diğer parametreler bakımından önemli bir fark bulunmamıştır ( $p>0.05)$.

Yaşam kalitesi alt ölçeklerinin bazı parametreler ile ilişkisi Tablo 4’te gösterilmiştir. Madde bağımlılarında fiziksel fonksiyon alt ölçeği puanı ile Basitleştirilmiş Beslenme İştah Anketi puanı ( $\mathrm{r}=0.233)$, BKİ $(\mathrm{r}=0.197)$ ve diyet çeşitliliği skoru ( $\mathrm{r}=0.153)$ arasında pozitif, SNAQ puanı ( $r=-0.278)$ ile negatif yönlü zayıf ilişki olduğu belirlenmiştir $(\mathrm{p}<0.05)$. Canlllık ve SNAQ arasında yapılan değerlendirmede negatif yönlü zayıf ilişki saptanmıştır $(r=-0.213, p<0.01)$. Madde kullanan bireylerde ruhsal sağllk düzeyi ile iştah durumu arasında pozitif ( $r=0.247$ ), ruhsal sağllk ve
BKİ ( $\mathrm{r}=0.193$ ) arasında pozitif yönlü zayıf bir ilişki olduğu bulunmuştur ( $\mathrm{p}<0.05)$. Ruhsal sağlık ve SNAQ $(r=-0.217)$ ve sosyal işlevsellikle SNAQ arasında ise negatif yönlü önemli ilişki saptanmıştır ( $r=-0.217)$ $(\mathrm{p}<0.05)$.

Alkol bağımlılarında ruhsal sağlık ve iştah arasında pozitif, SNAQ arasında negatif yönlü zayıf ilişki belirlenmiştir (sırasıyla $r=0.299$ ve $r=-0.374, p<0.05$ ). Alkol bağımlılarında sosyal işlev ile BKİ ( $r=-0.311)$ ve ÜOKÇ ( $\mathrm{r}=-0.432)$ arasında negatif, genel sağlık algısı ve DDS ( $\mathrm{r}=0.337)$ arasında pozitif yönlü zayıf ilişki bulunmuştur ( $\mathrm{p}<0.05)$. 


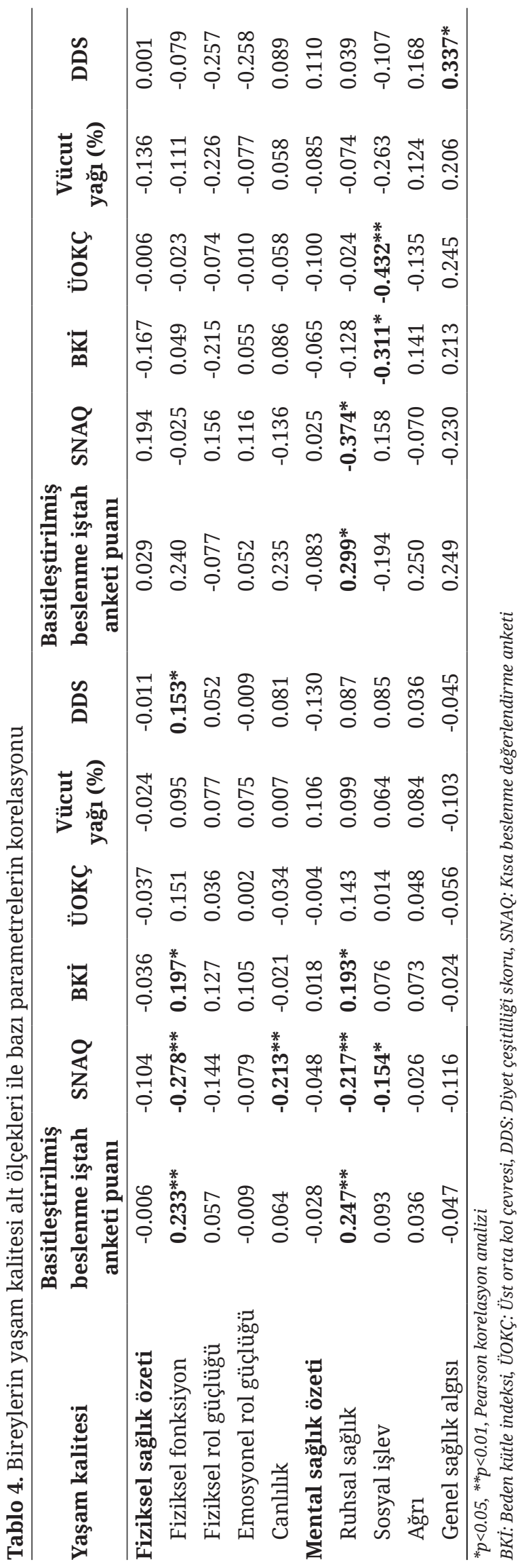

\section{TARTIŞMA}

Alkol ve madde bağımlılığı olan bireyler üzerinde yapılan bu çalışmada her iki grubun da yaklaşık \%70'inde ağır malnütrisyon ve \%90'ında ise iştahın bozulmasına bağlı olarak gelecek 6 ayda önemli düzeyde ağırlık kaybı riski bulunduğu belirlenmiştir. Ayrıca her iki grubun diyet çeşitliliğinin yetersiz olduğu ve her iki grupta da tek öğün beslenme yaygın olmakla birlikte alkol bağımlılarında daha yüksek olduğu saptanmıştır. Bunun yanında madde bağımlılarının antropometrik ölçümleri ve vücut bileşimi değerlerinin alkol kullanan bireylerden daha düşük olduğu belirlenmiştir. Her iki grubun yaşam kalitesi puanlarının düşük olduğu ve madde bağımlılarında fiziksel fonksiyonlar ile iştah durumu, malnütrisyon, BKİ ve DDS arasında, alkol bağımlarında sosyal işlevsellik ile BKİ ve ÜOKÇ arasında ve ruhsal sağlık ile iştah durumu ve malnütrisyon arasında ilişki bulunmuştur.

Alkol ve madde bağımlılarında malnütrisyon önemli sorunlardan biri olarak öne çıkmaktadır. Alkol bağımlılarında yapılan araştırmalarda bireylerde malnütrisyon oranının \%8.9-57.0 aralığında değiştiği görülmektedir (17-19). Bu çalışmada bireylerin önemli bir kısmında ağır malnütrisyon olduğu ve son 6 aylık süreçte önemli düzeyde ağırlık kaybettikleri belirlenmiştir. Hastalarda artan iştahsızlık nedeniyle tedavi olmazlarsa vücut ağırlık kayıp riskleri göz önüne alındığında malnütrisyon sıklı̆ı̆ını artacağı görülmektedir.

Kronik alkol kullanımı ağız, özofagus, mide ve bağırsaklarda hasar, bakteriyel aşırı birikme ve kanser gibi sorunlara neden olmaktadır (18). Ortaya çıkan bu sorunlar alkol bağımlılarında iştah kaybı, çeşitli gastrointestinal sorunlar ile besin ögelerinin sindirim ve emilimlerinde bozulmaya neden olarak malnütrisyon gelişimine yol açmaktadır $(17,20)$. $\mathrm{Bu}$ çalışmada dikkat çeken bir nokta da alkol bağımlılarının yüksek oranda etanol almalarına rağmen son 6 ayda vücut ağırlıklarının \%10'unu kaybetmiş olmalarıdır. Bireylerdeki artmış enerji alımına karşılık, azalan vücut ağırlığı bir paradoks 
olarak değerlendirilmektedir. $\mathrm{Bu}$ durumun altında yatan temel etmenin kronik alkoliklerde etanolün oksidasyonu için mikrozomal etanol okside edici sistemin devreye girmesi olduğu düşünülmektedir $(17,21)$.

Daha önce de belirtildiği gibi alkol ve madde kullanımı bireylerin enerji ve besin ögesi alımlarını olumsuz yönde etkileyebilmektedir $(22,23)$. Bu çalışmada bireylerin besin ögesi alımlarının ve diyet kalitesinin yeterliliğini göstermede etkili bir yöntem olan DDS kullanılmıştır $(24,25)$. Her iki grupta da DDS’nin yüksek oranda yetersiz olması önceki çalışmaları desteklemektedir ve bağımlıların günde sadece bir öğün yemek yemesi diyet çeşitliliği skorunun düşük bulunmasının en önemli nedenlerinden birisidir.

Alkol ve madde bağımlılarının büyük çoğunluğu her gün yemek yemediğini veya genellikle geceleri geç saatte olmak üzere bu çalışmadakine benzer şekilde özellikle alkol bağımlıları günde bir öğün tükettiklerini ifade etmiştir (17,23,26). Bağımlı bireyler yemeklerin ilgilerini çekmediğini ve yemek yeme keyfi yaşamadıklarını, alkol veya maddenin kendileri için yiyeceklerden çok daha fazla önemli olduğunu söylemektedir $(7,23)$. Bağımlıların, yemek yemeyi azaltma davranışındaki diğer nedenlerin depresyon, yeme bozukluları ve sağlık sorunları olduğu belirlenmiştir $(27,28)$. Bu nedenlerin dışında besin kısıtlamasının bireylerde madde yanıtını arttırdığı, bu nedenle bireylerin maddenin ödüllendirme etkisini arttırmak ve/veya uzatmak için besin kısıtlaması yaptıkları bildirilmiştir (29).

$\mathrm{Bu}$ çalışmada madde bağımlılarının BKİ değerleri ve antropometrik ölçümleri alkol bağımlılarından önemli düzeyde daha düşük bulunmuştur. Her iki grupta da bireylerin büyük çoğunluğu normal BKI aralığında yer alırken, madde bağımlılarında zayıf bireylerin oranının alkol bağımlılarından daha fazla olduğu görülmüştür. Yapılan çalışmalar bu çalışma ile benzer şekilde alkol kullanan bireylerde hafif şişman ve obez olma riskinin arttığını, madde bağımlılarında ise madde kullanımı ile BKİ arasında negatif yönlü bir ilişki olduğunu göstermiştir $(30,31)$.
Alkol ve madde bağımlılarında yaşam kalitesini değerlendiren çalışmalarda bireylerin genel, fiziksel ve ruhsal sağllk ile sosyal fonksiyonlar alt ölçeklerin puanlarının sağlıklı bireylerden düşük olduğu, bağımlılık sürecinin başlamasıyla birlikte ruhsal ve fiziksel sorunlarında başladı̆̆ı, bağımlılık şiddetinin artışı ve bağımlılık süresinin uzunluğunun semptomları etkilediği ve tedavi sürecine katılma ile birlikte tüm bu ölçeklerin puanlarında önemli derecede düzelmeler olduğu saptanmıştır (32-34).

$\mathrm{Bu}$ çalışmada madde kullanan bireylerde malnütrisyon, iştah ve BKİ değerleri fiziksel fonksiyon, canlılık, ruhsal sağlık ve sosyal işlevlerde bozulmayla ilişkili bulunurken, alkol kullanan bireylerde iştah, malnütrisyon, BKİ ve DDS'nin sadece ruhsal durumla ilgili alt ölçekleri oluşturan ruhsal sağlık, sosyal işlev ve genel sağlık algısı ile ilişkili olduğu belirlenmiştir. Bireylerin beslenme durumu ve günlük diyetle besin ögesi alım düzeyleri ruhsal sağlığı ve psikiyatrik bozuklukların gelişimini etkileyen önemli etmenlerdir (35).

$\mathrm{Bu}$ çalışmada da hem alkol bağımlılarında hem de madde bağımlılarında malnütrisyon riskinin artmasıyla ruhsal sağlık skorunun azaldığı saptanmıştır. Alkol ve madde bağımlılarında komorbid gelişen depresyon, bipolar bozukluk, travma sonrası stres bozukluğu ve anksiyete bozuklukları gibi ruhsal hastalıklar yaygın olarak görülmektedir $(36,37)$. Bu araştırmanın sonuçları alkol ve madde bağımlılarında malnütrisyon ve iştahsızlığın artmasının bu bireylerde ruhsal sorunların gelişmesine veya var olan ruhsal sorunların şiddetlenmesine neden olabileceğini düşündürmektedir.

Madde bağımlılığı insan sağlığını tüm yönleriyle olumsuz etkileyen önemli bir halk sağlığı sorunudur. Bağımlılık yapan çok çeşitli maddenin var olması ve bunların sahip olduğu farklı farmakolojik özellikler bireylerde malnütrisyondan obeziteye kadar değişen beslenmeyle ilgili sorunların oluşmasına neden olmaktadır. Bu sorunlar bireylerde komorbid hastalık riskini arttırırken, madde kullanımının kendi doğasında bulunan diğer hastalıklarla birlikte 
mortalite hızının artmasına neden olmaktadır. Bu araştırma kapsamında elde edilen sonuçlar alkol ve madde bağımlılarının beslenme durumunun ve alışkanlıklarının oldukça kötü olduğunu gösteren önemli sonuçlar içermektedir. Tüm dünyada olduğu gibi maalesef ülkemizde de alkol ve madde bağımlılığında son yıllarda belirgin bir artış söz konusudur. Bu bağlamda bu çalışmanın bağımlı gruplardaki beslenme durumunun ve alışkanlıkların değerlendirilmesi ve gruplar arasındaki farkların belirlenmesi yanında daha sonraki çalışmalara da yol gösterici olması açısından son derece önemli olduğu düşünülmektedir. Bunun yanında tedaviye alınan kişilerde mutlaka beslenme durumu değerlendirilmeli ve farmakolojik tedavinin yanında kişiye özel bir beslenme programı uygulanmalı, iyi tasarlanmış beslenme ve davranış değişikliği eğitimleri verilmelidir.

Çıkar çatışması - Conflict of interest: Yazarlar çıkar çatışması olmadığını beyan ederler. - The authors declare that they have no conflict of interest.

\section{KAYNAKLAR}

1. Konkolÿ TB, Hodgins DC, Wild TC. Co-occurring substance-related and behavioral addiction problems: a person centered,lay epidemiology approach. J Behav Addict 2016;5(4):614-2062.

2. Schulte TM, Hser Y. Substance use and associated health conditions throughout life span. Public Health Rev 2014; 35(2).

3. World Health Organization, Funding mechanisms for the prevention and treatment of alcohol and substance use disorders http://www.who.int/substance_abuse/ activities/fadab/msb_adab_funding.pdf?ua $=$. Accessed August 6, 2018.

4. United Nations Office on Drugs and Crime. 2018. World Drug Report 2018. Available at: https://www.unodc.org/ wdr2018/prelaunch/WDR18_Booklet_1_EXSUM.pdf. Accessed August 6, 2018.

5. Barry D, Petry NM. Associations between body mass index and substance use disorders differ by gender: results from the national epidemiologic survey on alcohol and related conditions. Addict Behav 2009;34(1):51-60.

6. Lieber SC. Relationship between nutrition, alcohol use and liver disease. Alcohol Res Health 2003;27(3):220-
231.

7. Thorley H, Porter K, Fleming C, Jones T, Kesten J, Marques $\mathrm{E}$, et al. Interventions for preventing or treating malnutrition in problem drinkers who are homeless or vulnerably housed:protocol for a systematic review. Syst Rev 2015;4:31.

8. Pekcan G. Beslenme durumunun saptanması. Baysal A, Aksoy M, Besler T, Bozkurt N, Keçecioğlu S, Kutluay Merdol T ve arkadaşları (editörler). Diyet El Kitabı. 11. baskı. Hatiboğlu Basın ve Yayım San. Tic. Ltd. Şti, Ankara. 2011. s. 67-142.

9. WHO. Obesity: Preventing and managing the global epidemic. Available at: http://www.who.int/nutrition/ publications/obesity/WHO_TRS_894/en/. Accessed August 6, 2018.

10. Ashwell M, Hsieh SD. Six reasons why the waist-to height ratio is a rapid and effective global indicator for health risks of obesity and how its use could simplify the international public health message on obesity. Int J Food Sci Nutr 2005; 56(5):303-307.

11. Wilson M, Thomas D, Rubenstien, Chibnall J, Anderson S, Baxi A, et al. Appetite assessment: simple appetite questionnaire predicts weight loss in communitydwelling adults and nursing home residents. Am J Clin Nutr 2005;82(5):1074-1081.

12. Nakatsu N, Sawa R, Misu S, Ueda Y, Ono. Reliability and validity of the Japanese version of the simplified nutritional appetite questionnaire in communitydwelling older adults. Geriatr Gerontol Int 2015;15(12):1264-1269.

13. Kruizenga HM, Van Tulder MW, Seidell JC, Thijs A, Ader HJ, Van Bokhorst-de van der Schueren MA. Effectiveness and cost-effectiveness of early screening and treatment of malnourished patients. Am J Clin Nutr 2005;82(5):1082-1089.

14. Drimie S, Faber M, Vearey J, Nunez, L. Dietary diversity of formal and informal residents in Johannesburg, South Africa. BMC Public Health 2013;13:911.

15. Ware JE, Sherbourne CD. The MOS 36-item short-form health survey (SF-36). I. Conceptual framework and item selection. Med Care 1992;30:473-483.

16. Kocyigit H, Aydemir O, Fisek G, Olmez N, Memis A. Validity and reliability of Turkish version of Short form 36:A study of a patients with romatoid disorder. İlaç ve Tedavi Derg 1999;12:102-106.

17. Santoloria-Fernandez FJ, Sirvent JL, Reimers C, Lopez J, Hernandez JA, Rodríguez-Moreno F, et al. Nutritional assessment and drug addicts. Drug Alcohol Depend 1995;38(1):11-18.

18. Manari P, Preedy VR, Peters TJ. Nutritional intake of hazardous drinkers and dependent alcoholics in the UK. Addict Biol 2003;8(2):201-210. 
19. Gautron MA, Questel F, Lejoyeux M, Belliver F, Vorspan F. Nutritional status during inpatient alcohol detoxification. Alcohol Alcohol 2018;53(1):64-70.

20. Bode C, Bode JC. Alcohol's role in gastrointestinal track disorders. Alcohol Health Res W 1997;21(1):76-83.

21. Jequiér E. Alcohol intake and body weight: a paradox. Am J Clin Nutr 1999;69(3):173-174.

22. Gonzales-Reimers E, Campelo E, Santolaria-Fernandez F, Sanchez-Perez M, Gomez Rodriguez M, Vina-Rodriguez J. Prognostic value of nuritional status in alcoholics, asssessed by double-energy x-ray absorptiometry. Alcohol Alcohol 2008;43(3):314-319.

23. Neale J, Nettleton S, Pickering L, Fischer J. Eating patterns among heroin users: a qualitative study with implications for nutritional interventions. Addiction 2012;107(3):635-641.

24. Azadbakht L, Esmaillzadeh A. Dietary diversity score is related to obesity and abdominal obesity among Iranian female youth. Public Health Nutr 2011;14(1):62-69.

25. Poorrezaeian M, Siassi F, Qorbani M, Karimi J, Koohdani F, Aseyesh H. Association of dietary diversity score with anxiety in women. Psychiatry Res 2015;230(2):622-627.

26. Sæland M, Haugen M, Eriksen FL, Smehaugen A, Wandel M, Böhmer T. Living as a drug addict in Oslo, Norway- a study focusing in nutrition and health. Public Health Nutr 2008;12(5):630-636.

27. Satre DD, Leibowitz AS, Mertens JR, Weisner C. Advising depression patients to reduce alcohol and drug use: factors associated with provider intervention in outpatient psychiatry. Am J Addict 2014;23(6):570-575.

28. Suzuki K, Takeda A, Yoshino A. Mortality 6 years after inpatient treatment of female Japanese patients with eating disorders associated with alcoholism. Psychiatry Clin Neurosci 2011;65(4):326-332.
29. McIlwraight F, Betts KS, Jenkinson R, Hickey S, Burns L, Alati R. Is low BMI associated with specific drug use among injecting drug users? Subst Use Misuse 2014;49:374-382.

30. Lucasiewicz E, Mennen LI, Bertrais S, Arnault N, Preziosi $\mathrm{P}$, Galan P, et al. Alcohol intake in relation to body mass index and waist-to-hip ratio: the importance of type of alcoholic beverage. Public Health Nutr 2005;8(3):315320.

31. Blüml V, Kapusta N, Vyssoki B, Kogoj D, Walter H, Lesch, OM. Relationship between substance use and body mass index in young males. Am J Addict 2011;21(1):72-77.

32. Lahmek P, Berlin I, Michel L, Berghout C, Meunier N, Aubin HJ. Determinants of improvement in quality of life of alcohol-dependent patients during an inpatient withdrawal. Int J Med Sci 2009;6(4):160-167.

33. Dawson DA, Li TK, Chou SP, Grant BF. Transitions in and out of alcohol use disorders: Their associations with conditional changes in quality of life over a 3-year follow-up interval. Alcohol Alcohol 2009;44(1):84-92.

34. Levola J, Aaolta M, Holopainen A, Cieza A, Pitkänen T. Health-related quality life in alcohol dependence: A systematic literature review with a specifi c focus on the role of depression and other psychopathology. Nord J Psychiatry 2014; 68(6):369-384.

35. Gadit M. Nutritional factors in mental health: Does 'Epigenetics' provide a road map? J Pak Med Assoc 2011;61(8):823-824.

36. Sanchez-Pena JF, Alvarez-Cotoli P, Rodriguez-Solano JJ. Psychiatric disorders associated with alcoholism: 2 year follow-up of treatment. Actas Esp Psiquiatr 2012;40(3):129-135.

37. Langas AM, Malt UF, Opjordsmoen S. Comorbid mental disorders in substance users from a single catchment area-a clinical study. BMC Psychiatry 2011;11:25. 